\title{
DO PASTICHE SOBRE SI: ESTILO E ANTROPOMORFISMO NO “NAUSICA”, DE ULYSSES
}

\author{
PASTICHE TURNED UPON ITSELF: STYLE AND \\ ANTROPOMORPHISM IN ULYSSES' "NAUSICAA"
}

\author{
Tauan Fernandes Tinti* \\ Universidade Estadual de Campinas \\ Fabio Akcelrud Durão \\ Universidade Estadual de Campinas
}

RESUMO: Este trabalho parte da ideia apresentada por Kenner de que o Ulysses de Joyce é constituído por duas vozes narrativas que cumprem funções divesas em sua estrutura. A partir da verificação de certas inconsistências na caracterização da protagonista de "Nausicaa", é defendida então a hipótese de que o episódio seria um caso limite da violência paródica de Ulysses, onde o romance se volta contra sua própria dinâmica básica de funcionamento, trazendo consequências variadas para seus processos de constituição de sentido.

PALAVRAS-CHAVE: Ulysses. "Nausicaa”. Hugh Kenner. Arranjador. Identificação.

\footnotetext{
* Possui graduação em Letras pela Universidade Federal de São Carlos (2008) e mestrado em Teoria e História Literária pela Universidade Estadual de Campinas (2011). É Doutorando em Teoria Literária pela Unicamp. Campinas, São Paulo, Brasil. E-mail: tauantinti@gmail.com

** Possui mestrado em Teoria Literária pela UNICAMP. Doutorado em Literatura em Duke University e pós-doutorado na Universidade Estadual Paulista Júlio de Mesquita Filho (UNESP). É Livre-Docente do Departamento de Teoria Literária da Unicamp. Campinas, São Paulo, Brasil. E-mail: fadurao@yahoo.com
} 
ABSTRACT: This paper initially explores Hugh Kenner's idea that Joyce's Ulysses is structured by two main narrative voices that fulfill different functions. In examining its dynamics in "Nausicaa", and noticing certain issues in the characterization of its leading figure, we put forth the hypothesis that "Nausicaa" is a borderline case of Ulysses' parodic violence, a moment when the novel turns its forces against itself. Finally, we claim that such a gesture brings important consequences to the way the novel creates meaning KEYWORDS: Ulysses. "Nausicaa”. Hugh Kenner. Arranger. Identification. 


\section{INTRODUÇÃO}

“Mas quem era Gerty?", logo pergunta o narrador de "Nausicaa"1, décimo terceiro episódio do Ulysses de James Joyce. Como não poderia deixar de ser, trata-se de uma óbvia pergunta retórica, que serve apenas para apresentar uma caracterização da heroína e protagonista (mesmo que somente da parte inicial deste episódio) Gerty MacDowell, expandindo o tom pomposo rapidamente estabelecido nas pouco mais de duas páginas que a antecedem, desse modo assinalando que a narração se encontra mais uma vez marcada pela paródia. Já o episódio anterior, "Ciclope”, situado no pub de Barney Kiernan, demonstrara a propensão desse narrador, tornado proteico no mínimo desde o episódio dos "Rochedos errantes", para a imitação zombeteira e por vezes desmotivada de vozes e estilos alheios, alternando entre o ataque

1 Em Joyce's Voices, Hugh Kenner (1978, p. 59), ressalta que os títulos dos episódios, que colocam em evidência a intenção de se estabelecer paralelos de algum tipo entre Ulysses e a Odisseia, foram fornecidos pelo próprio Joyce para certos membros de seu círculo para que fossem divulgados entre leitores e críticos de Ulysses. Porém, tais títulos foram utilizados a partir de então de forma tão extensa que podemos mesmo nos esquecer de que não estão contidos dentro do romance, que se limita em apontar para o paralelo homérico apenas através de seu título. 
implacável contra Bloom, encabeçado pelo até então inédito narrador em primeira pessoa e pelas falas do Cidadão, e breves passagens altamente cômicas parodiando gêneros como documentos legais ou textos jornalísticos (exaustivamente elencados em Ulysses Annotated, o valioso guia de referências para o romance de Joyce elaborado por Gifford (2008, p. 313-380), oriundas não se sabe bem de onde ${ }^{2}$. Porém, diferentemente do que ocorre em "Ciclope", temos na presença de Gerty uma motivação a princípio clara para o exercício estilístico do narrador. Mesmo seu nome parece servir de cifra, apontando diretamente para a Gertrude (Flint) de The Lamplighter, um romance sentimental americano - e proto-bestseller - escrito por Susanna Cummins em 1854 que consta no rol de emocionantes leituras citadas por Gerty no episódio e acolheria sem cerimônias uma frase como a que abre o episódio de Ulysses em questão: "O entardecer estival começara a envolver o mundo em seu misterioso abraço" (JOYCE, 2012, p. 550) / "The Summer Evening had begun to fold the world in its mysterious embrace" (JOYCE, 1961, p.346) ${ }^{3}$. Sua imprecisão calculada, marcada por uma prosopopeia que sugere um clima vagamente acolhedor, esvazia do adjetivo "misterioso" qualquer conotação ameaçadora e a substitui por algo que no máximo pertenceria à esfera do exótico - como um encontro romântico "inesperado" que não demora a se realizar.

O único ruído autoconsciente produzido pela maquinaria narrativa nessas páginas iniciais seria o do balbucio do bebê Boardman - "U dói u dói duaba" (JOYCE, 2012, p.551) / "A jink a jink a jawbo" (JOYCE, 1961, p. 346) -, que parece mais próximo do som produzido por um bebê real do que seria esperado de uma narrativa nesses moldes, mais afeita a representações da ordem de um "gugu dadá". A transcrição gráfica do som do bebê Boardman indiretamente sugere a existência de acontecimentos efetivos se

2 Em Ulysses, Kenner (1980) aponta que, nos esboços iniciais de "Ciclope”, Stephen Dedalus também se encontrava no pub de Barney Kiernan, funcionando assim como possível fonte dos interlúdios paródicos. A decisão de Joyce de retirá-lo dessa cena nas reformulações posteriores do episódio serviria então, entre outros motivos possíveis, como forma de sublinhar a ausência de motivação narrativa para tais interlúdios, que desse modo estariam aparentemente subordinados apenas às vicissitudes do próprio estilo.

3 Todas as citações em português de Ulysses são retiradas da tradução de Caetano Galindo, publicada pela Penguin/Cia. das Letras em 2012 (JOYCE, 2012); as citações em inglês são retiradas da edição Vintage de 1961 (JOYCE, 1961). 
desenrolando por trás da cortina de estilo insípido, e é um indício inicial de algo no episódio que não pode ser integralmente atribuído à emulação do estilo de The Lamplighter, que, por sua vez, parece nesse ponto justificada pela proximidade entre o narrador e Gerty. Mas quem era Gerty?

Gerty MacDowell, que estava sentada junto de suas companheiras, absorta em seus pensamentos, olhar perdido longe na distância, era com toda justiça o mais belo espécime da cativante feminilidade irlandesa que se pode desejar. Era declarada linda por todos os que a conheciam muito embora, como sempre dissessem, tivesse mais de Giltrap que de MacDowell. Seu talhe era esguio e gracioso, tendendo até à fragilidade mas aquelas cápsulas de ferro que andava tomando fizeram-lhe um bem incrível muito melhor que as pílulas para senhoras da viúva Welch e ela estava muito melhor daqueles corrimentos que tinha antes e daquela sensação de canseira. A palidez de cera de seu rosto era quase espiritual em sua pureza ebúrnea embora o botão de rosa de sua boca fosse um legítimo arco de Cupido, helenicamente perfeito. Suas mãos eram de um alabastro finamente riscado pelos traços das veias com dedos longos e finos brancos como o sumo de limão e a rainha dos unguentos podiam fazê-los embora não fosse verdade que ela usasse luvas de pelica no leito ou fizesse escaldapés com leite. (JOYCE, 2012, p. 553-4)

Gerty MacDowell who was seated near her companions, lost in thought, gazing far away into the distance, was in very truth as fair a specimen of winsome Irish girlhood as one could wish to see. She was pronounced beautiful by all who knew her though, as folks often said, she was more a Giltrap than a MacDowell. Her figure was slight and graceful, inclining even to fragility but those iron jelloids she had been taking of late had done her a world of good much better than the Widow Welch's female pills and she was much better of those discharges she used to get and that tired feeling. The waxen pallor of her face was almost spiritual in its ivorylike purity though her rosebud mouth was a genuine Cupid's bow, Greekly perfect. Her hands were of finely veined alabaster with tapering fingers and as white as lemon juice and queen of ointments could make them though it was not true that she used to wear kid gloves in bed or take a milk footbath either. (JOYCE, 1961, p. 348)

Conforme notado por Thomas Karr Richards (1985, p. 757), com a descrição típica de uma heroína bela, perfeita e admirada por todos, podería- 
mos ter a impressão de estar lendo The Lamplighter até a primeira conjunção "mas" / "but", que interrompe abruptamente a postura elegante do narrador e a substitui por um acúmulo desconjuntado de considerações sobre objetos que pertencem menos ao mundo dos romances sentimentais do que ao dos anúncios de revistas; de acordo com o crítico, "passamos da beleza frágil para a sua manutenção material”, com uma série de expressões retiradas de slogans de produtos encontrados em revistas para moças que circulavam na Irlanda da época, como a Pearson's Magazine ou The Lady's Pictorial (sendo ambas citadas posteriormente na narrativa). ${ }^{4}$ Educados pela dinâmica estabelecida ao longo dos episódios iniciais do romance, somos levados a entender que a alteração na sintaxe e no tipo de vocabulário da frase a partir da conjunção "mas" / "but" assinala a transição de um registro narrativo externo a Gerty para seu tipo particular de monólogo interior, diverso tanto do de Stephen quanto do de Bloom.

Após a frase seguinte, que retoma o estilo elevado, ocorre uma quebra semelhante à anterior e igualmente abrupta, dessa vez marcada pela conjunção "embora" / "though", e os objetos de anúncios novamente se sobrepõem de forma apressada à voz narrativa dominante, que agora cede um pouco mais de terreno: mesmo antes da conjunção temos a expressão "rainha dos unguentos" / "queen of ointments", que é, de acordo com Gifford (2008, p. 403), um slogan da marca Beetham's Larola. E, para Karr Richards (1985, p. 768), o slogan "queen of ointments" também apontaria para certo impulso religioso, sempre a ressurgir ao longo do episódio, pré-enxertando um termo extra na ladainha de Nossa Senhora que será entoada posteriormente pelo narrador ("Rainha dos anjos, rainha dos patriarcas, rainha dos profetas [...]" [JOYCE, 2012, p. 569] / "Queen of angels, queen of patriarchs, queen of prophets [...]” (JOYCE, 1961, p. 359), e que assim ecoaria retroativamente algo como um jingle comercial.

Por sua vez, em Joyce’s Voices (1978) Hugh Kenner também se detém sobre o parágrafo de apresentação de Gerty MacDowell, mas como forma de

\footnotetext{
4 Vale notar que a tradução de Galindo para a irrupção de frases desconexas após a conjunção "mas" se aproxima mais de uma conversa coloquial, ou de uma propaganda boca a boca, com sua "sensação de canseira", do que de uma possível frase de anúncio. A expressão "that tired feeling", por exemplo, é definida por Karr Richards (1985, p. 758) como "o pilar dos fabricantes de pílulas”.
} 
desenvolver seu célebre Princípio do Tio Charles: reproduzindo a metáfora utilizada pelo crítico, seria como se os personagens das narrativas de Joyce exercessem uma espécie de força gravitacional sobre seus narradores, que seriam deformados pela força de atração, tanto do ponto de vista lexical quanto sintático. Dito de outra forma, não haveria em Joyce um estilo narrativo neutro, mas, ao invés disso, um narrador que se deixa contaminar pelos personagens, assumindo elementos de suas dicções quando deles se aproxima e incorporando-os à tessitura narrativa até quando não está mergulhado em seus monólogos interiores. Desse modo, mesmo a sintaxe do narrador elevado deste parágrafo de apresentação estaria repleta de distorções operadas pela presença de Gerty: onde Karr Richards (1985, p. 758) vê uma abolição da sintaxe que deixa as mercadorias flutuando livres para Gerty (o que também não deixa de ser verdade), com um "either" final "deixado solto" e a conjunção "though" servindo para introduzir um non sequitur, Kenner (1978, p. 19) nota exatamente nas mesmas palavras uma tentativa de rebater fofocas maliciosas e uma afirmação petulante (e, poderia ser acrescentado, comicamente contraditória), feita por um narrador contaminado por Gerty, de que sua beleza seria algo como uma dádiva divina.

Contudo, o modelo apresentado por Kenner para os padrões narrativos de Joyce em Ulysses é consideravelmente mais complexo, e é necessário que ele seja explorado para que possamos avançar com a hipótese interpretativa deste trabalho, a saber, que "Nausicaa" pode ser interpretado como um dos casos limite da violência paródica de Ulysses, o ponto em que o romance volta suas forças contra sua própria dinâmica básica de funcionamento, e que tal gesto tem consequências variadas para seus processos de constituição de sentido.

\section{AS DUAS VOZES DE JOYCE}

Em Joyce’s Voices, Hugh Kenner (1978, p. 64-99) irá detectar a presença não de uma, mas de duas vozes narrativas coexistindo em Ulysses, ambas em alguma medida relacionadas ao Princípio do Tio Charles: "uma voz talvez mais hábil com arranjos de cena, e a outra com mais talento para a técnica 
lírica” (KENNER, 1978, p. 67). A primeira dessas vozes, responsável pela movimentação dos personagens, se deixa afetar mais facilmente por sua presença, compartilhando de seu vocabulário e sua sintaxe e garantindo acesso à interioridade de Bloom ou Stephen, seja por pistas lexicais espalhadas pela construção verbal, seja pelas transições rumo aos seus monólogos. Por sua vez, a segunda voz é capaz de se movimentar independentemente de qualquer personagem - ainda que também reaja a suas presenças - e é dotada de um virtuosismo minimalista ímpar, uma capacidade constante, relacionada à sua precisão vocabular, de atribuir o nome certo às coisas, garantindo por contraste a tudo o que dela se diferencia um caráter perifrástico (KENNER, 1978, p. 31). Essa segunda voz será reformulada, em um livro posterior de Kenner (1980, p. 61-71), com base em David Hayman (1982 [1970]), na figura do "arranjador", uma instância supranarrativa que independe do narrador comum e é capaz de organizar e comentar a ação como bem entende. Porém, apenas essa descrição das duas vozes não dá conta de suas vicissitudes no romance.

Tentar compreender a diferença entre as duas vozes - ou instâncias - narrativas por meio do estabelecimento de uma hierarquia entre elas apresenta um problema inicial relacionado à organização do Ulysses como um todo. Se seguirmos a sugestão de Kenner (1980, p. 61) em “The Arranger” e dividirmos o romance em duas partes, a primeira indo do início até "Rochedos errantes" e a segunda sendo composta pelos episódios restantes, não é difícil perceber a preponderância de cada uma delas nas duas partes do livro.

A primeira parte de Ulysses seria dominada pelo Princípio do Tio Charles, com um entrelaçamento constante de interior ("Xícara de chá logologo. Bom. Boca seca." [JOYCE, 2012, p. 163] / "Cup of tea soon. Good. Mouth dry." [JOYCE, 1961, p. 55]) e exterior (“Ah, olha só você aí, o senhor Bloom disse, voltando-se do fogo." [JOYCE, 2012, p. 163] / "O, there you are, $\mathrm{Mr}$ Bloom said, turning from the fire." [JOYCE, 1961, p. 55]) somado a interstícios de precisão telegráfica ("A gata andava rígida em torno de uma perna da mesa com o rabo para cima. - Mqnhao!" [JOYCE, 2012, p. 163] / "The cat walked stiffly round a leg of the table with tail on high. - Mkgnao!" [JOYCE, 1961, p. 55]) ou a momentos de ironia que dificilmente se justificam ("Ó EÓLIA HARPA!” [JOYCE, 2012, p. 261] / “O HARP EOLIAN!” [JOYCE, 
1961, p. 127], anuncia a manchete - visível apenas para os leitores de Ulysses, e para nenhum de seus personagens - que antecede o fio dental que faz os dentes do editor Myles Crawford ressoarem em "Éolo").

De outro lado, a segunda parte do romance inverte o espaço dedicado a cada uma dessas instâncias de organização da narrativa: em contraste com a logorreia do "Eu" não identificado de "Ciclope", Bloom surge como surpreendentemente lacônico. Ou, para dizer de outro modo, fazendo referência a um dos momentos mais brilhantes de "Ítaca", as perífrases que caracterizam seu pensamento "aquoso" e multiforme são constantemente suprimidas nos episódios posteriores de Ulysses, ao passo que o crescimento desenfreado da figura do arranjador faz com que ele abra mão de sua precisão econômica e se torne, ao contrário, uma instância quase insuportavelmente verborrágica. E é por meio dessa prolixidade sem sentido que são construídos muitos dos momentos verdadeiramente hilários do livro, dos sons do cachorro Garryowen, em "Ciclope", traduzidos em poema que "evoca as intricadas regras aliterativas e isossilábicas do englyn galês" (JOYCE, 2012, p. 505) / "recalls the intricate alliterative and isosyllabic rules of the Welsh englyn" (JOYCE, 1961, p. 312) à longa descrição da água a fluir de um reservatório distante até a torneira girada por Bloom em "Ítaca", passando por toda a escrita pernóstica de "Eumeu".

Além disso, pode-se argumentar que é justamente a presença agigantada da figura do arranjador na segunda parte do romance que torna possível perceber retroativamente sua presença nos interstícios da primeira parte, e, por sua vez, que a supressão de interioridades tão fortemente constituídas nos episódios iniciais por meio do entrelaçamento das diferentes camadas narrativas garante aos pequenos vislumbres que delas podemos entrever nos momentos mais caóticos de Ulysses uma pungência de intensidade semelhante à da admiração pelo virtuosismo minimalista do arranjador em sua primeira forma. Como exemplo desse segundo caso, teríamos o breve surgimento ao final de "Circe" da figura fantasmática e silenciosa de Rudy, o filho de Bloom morto com apenas onze dias de vida, cuja aparição, de veracidade no mínimo questionável, não volta a ser mencionada de nenhuma forma até o final do livro, sem que isso impeça que seu efeito - que certamente é responsável por muito do sofrimento do casal Bloom - perdure ao 
longo da experiência de leitura e ecoe até a declinação, em "Ítaca", "pronta, inexplicável, com amicabilidade, agradecidamente” (JOYCE, 2012, p. 982) / "promptly, inexplicably, with amicability, gratefully" (JOYCE, 1961, p. 695) de Stephen à proposta de asilo oferecida por Bloom.

Ou seja, para prosseguir com o argumento, estabelecer uma hierarquia que situe apenas uma das duas diferentes instâncias narrativas com relação à outra apresenta dificuldades relacionadas ao fato de elas estarem interligadas em um desequilíbrio variável, a preponderância de uma sobre a outra causando reverberações que produzem efeitos de sentido inesperadamente poderosos por todo o texto. Porém, se inserirmos a categoria dos personagens como terceiro termo em torno do qual as duas instâncias narrativas se hierarquizem, a diferença entre elas parece se tornar mais clara e produtiva. Assim, teríamos o primeiro narrador "convencional" - se é que o termo faz sentido nesse contexto - como uma voz subordinada às capacidades expressivas dos personagens dos quais se encontra próxima; Kenner certamente tem essa instância em mente ao afirmar que

Ninguém jamais superou a habilidade possuída por James Joyce de maquinar limites plausíveis para as habilidades expressivas, e, assim como no poema de Hynes [em "Dia de Hera na sala do comitê”, de Dublinenses], o parágrafo de Stephen [em Um retrato do artista quando jovem] avança até o limite da paródia sem que isso prejudique nossa consciência de que algo arrebatador aconteceu.

(KENNER, 1980, p. 9)

Já o arranjador estaria em uma posição superior à dos personagens, e isso em pelo menos dois sentidos. Em primeiro lugar, sua capacidade de organizar os elementos do enredo de forma a sugerir que o universo de Ulysses se diverte às custas das infelicidades de Bloom denota uma influência nos eventos muito acima de sua mera observação e descrição, com coincidências infelizes proliferando-se a todo instante, cujo efeito em Bloom vai da tensão proporcionada pela constante presença do amante de sua esposa Molly, Blazes Boylan, ou de toda a subtrama envolvendo o cavalo azarão Throwaway, 
que faz com que diversas pessoas acreditem que Bloom possui uma pequena fortuna (algo do qual ele não faz ideia), até a simples direção geral de conversas, que parecem sempre tocar indiretamente em pontos delicados de seu passado, como é o caso do ataque ao suicídio proferido na carruagem em "Hades", inevitavelmente despertando em Bloom a lembrança do suicídio de seu pai Virag.

Em segundo lugar, seu poder de expressão não é limitado pelo dos personagens, mas, ao contrário, demonstra a capacidade de sobrepujá-lo em diversos momentos da narrativa - dentre inúmeros exemplos, podemos ficar apenas com as falas prolixas de Bloom em "Eumeu", que reproduzem estranhamente os circunlóquios pernósticos do narrador como não o fazem em nenhum outro momento do romance ${ }^{5}$. Nos capítulos iniciais, quando suas capacidades ainda se mostram de modos mais sutis, podemos perceber as mãos do arranjador com mais facilidade nos momentos em que Bloom se encontra sozinho, por meio daquele seu virtuosismo minimalista em nomear as coisas sem margem de erro ou perífrase, algo que parece constantemente acima das capacidades vocabulares do protagonista de Ulysses. Mas isso não quer dizer que essa instância permaneça imune à influência dos personagens. $\mathrm{O}$ argumento de Kenner seria o de que, no limite, é precisamente o contato constante com as diversas subjetividades que permeiam o romance, e especialmente com as insuficiências, expressivas ou não, assinaladas por elas, que possibilita a percepção de que as verdades psicológicas de cada uma dessas personagens estão ligadas indissociavelmente à forma como se expressam. E é isto o que, para Kenner, deságua naquilo que o crítico define como um "pirronismo quase perfeito" (KENNER, 1978, p. 53): "uma posição filosófica coerente, que não é articulada em lugar algum pelo fato de o ceticismo não poder reconhecer seus próprios dogmas: a de que quando asserções não podem possuir substância, elas podem apenas possuir estilo" (KENNER, 1978, p. 55, grifo do autor).

5 É curioso notar que neste ponto o argumento inverso poderia ser apresentado: não se trataria do arranjador contaminando o discurso de Bloom, mas, ao contrário, de um esforço hercúleo - talvez fosse melhor dizer homérico - por parte deste em fingir conhecimentos que não possui com o intuito de impressionar seu novo companheiro "poeta e filósofo", e que este sim contaminaria o narrador, em uma versão particularmente exacerbada do Princípio do Tio Charles. 
E, se esse último argumento de Kenner soa como uma forma mais comportada de uma formulação geral do tipo "tudo é linguagem”, é porque em seu momentos mais extremos ele consiste exatamente nisso. Assim como no caso da distinção entre as duas instâncias narrativas, o crítico irá reformular e apresentar uma nova versão desse argumento em seu Ulysses (KENNER, 1980, p. 156): “Ulysses insiste acima de tudo no fato de que não há nele nenhum Bloom, nenhum Stephen, nenhuma Molly, nenhuma Dublin, mas há simplesmente linguagem".

A imagem construída por seu percurso interpretativo, então, acaba por se aproximar de algo como um curto-circuito: Joyce cria os personagens e descreve as situações a partir de suas perspectivas, e em consequência de sua capacidade de transitar com tamanha maestria por diferentes perspectivas surge uma voz consciente desse processo, que começa gradualmente a chamar atenção para si e para o fato de que tanto os personagens quanto as situações que vivem são criação sua, e nada além disso. O que inicialmente é construído como uma relação de adequação entre personagem e linguagem via Princípio do Tio Charles por fim se revelaria como uma estrutura ilusória, que passaria a dar margem a experimentos de inadequação entre linguagem e situação narrativa, e em última instância à arbitrariedade estilística cujo melhor exemplo é provavelmente o episódio "Gado ao sol".

É por essa trilha que finalmente podemos retornar a Gerty MacDowell e à cilada interpretativa armada por Hugh Kenner. Porque, se a formulação do parágrafo acima faz sentido, teríamos uma passagem em Ulysses da adequação entre estilo e situação - que domina os episódios iniciais - a uma arbitrariedade cuja nota fundamental é a paródia desmotivada, mas em "Nausicaa” um caso extremo de paródia que parece encontrar uma motivação narrativa na figura de Gerty. E, se seria natural assumir que se trata de um ponto médio em um processo de transição de um extremo a outro, pois em nenhum outro momento do livro a adequação entre estilo e situação narrativa se dá pela via da paródia de forma tão pronunciada - ao contrário, a tarefa de encontrar justificativas para outras ocorrências desse procedimento demanda bastante esforço interpretativo -, buscamos aqui situar "Nausicaa" em posição bastante diversa. 


\section{GERTY MACDOWELL E O ARRANJADOR}

"Nausicaa" nos dá a impressão de que tanto Gerty MacDowell quanto James Joyce leram The Lamplighter, mas que dele tiraram coisas diferentes: Gerty, ao menos uma pequena parte da sua visão de mundo; Joyce, um estilo a ser imitado e, no limite, a própria Gerty. Logo após mencionar o livro "da senhorita Cummins", o narrador afirma que a personagem possui sonhos escondidos e aspirações artísticas, mas logo tropeça novamente na descrição de coisas. O trecho é longo, mas será retomado continuamente ao longo da argumentação, e por isso merece ser citado por completo:

Quão comovente era o quadro ali nos albores do crepúsculo, uma última visão de Erin, o tocante bimbalhar daqueles sinos vesperais e ao mesmo tempo um morcego saiu voando do campanário coberto de hera atravessando o luscofusco, para cá, para lá, com um gritinho perdido. E ela conseguia ver na distância as luzes dos faróis tão pitorescas que ela adoraria fazê-las com uma caixa de tintas porque era mais fácil do que fazer um homem e logo o acendedor de lampiões faria sua ronda passando pelo campossanto da igreja presbiteriana e ao longo da ensombrecia Tritonville Avenue onde caminhavam os casais e acendendo o lampião próximo à janela dela onde Reggy Wylie costumava rodar com sua bicicleta nova como ela leu naquele livro $O$ acendedor de lampiões da senhorita Cummins, autora de Mabel Vaughan e outras estórias. Pois Gerty tinha seus sonhos de que ninguém suspeitava. Ela adorava ler poesia e quando ganhou de lembrança de Bertha Supple aquele álbum de confidências com a capa em rosacoral para escrever seus pensamentos ela o depôs na gaveta de sua penteadeira que, ainda que não tendesse ao luxo, era escrupulosamente organizada e limpa. Era ali que guardava sua arca do tesouro de 
menina, os pentes de casco de tartaruga, seu distintivo das filhas de Maria, a fragrância de rosas brancas, o Sobrancelinda, seu bauzinho de alabastro e as fitas para trocar quando suas coisas voltavam da casa da lavadeira e havia lindos pensamentos lá inscritos em uma tinta violeta que ela comprara no Hely's da Dame Street pois ela sentia que também ela seria capaz de escrever poesia se apenas pudesse se expressar como aquele poema que lhe calara tão fundo que ela chegara a copiá-lo do jornal que encontrou certa noite junto aos vasos de plantas. És real, meu ideal? Era o título de Louis J. Walsh (...)

(JOYCE, 2012, p. 574)

How moving the scene there in the gathering twilight, the last glimpse of Erin, the touching chime of those evening bells and at the same time a bat flew forth from the ivied belfry through the dusk, hither, thither, with a tiny lost cry. And she could see far away the lights of the lighthouses so picturesque she would have loved to do with a box of paints because it was easier than to make a man and soon the lamplighter would be going his rounds past the Presbyterian church grounds and along by shady Tritonville avenue where the couples walked and lighting the lamp near her window where Reggy Wylie used to turn his freewheel like she read in that book The Lamplighter by Miss Cummins, author of Mabel Vaughan and other tales. For Gerty had her dreams that no-one knew of. She loved to read poetry and when she got a keepsake from Bertha Supple of that lovely confession album with the coralpink cover to write her thoughts in she laid it in the drawer of her toilettable which, though it did not err on the side of luxury, was scrupulously neat and clean. It was there 
she kept her girlish treasures trove, the tortoiseshell combs, her child of Mary badge, the whiterose scent, the eyebrowleine, her alabaster pouncetbox and the ribbons to change when her things came home from the wash and there were some beautiful thoughts written in it in violet ink that she bought in Hely's of Dame Street for she felt that she too could write poetry if she could only express herself like that poem that appealed to her so deeply that she had copied out of the newspaper she found one evening round the potherbs. Art thou real, my ideal? it was called by Louis J. Walsh (...) (JOYCE, 1961, p. 363-364)

A primeira coisa que salta aos olhos no trecho citado é a relativa perda de controle do narrador sob o material narrado, que cede cada vez mais espaço para o que se assemelha a um discurso indireto livre que tem sua heroína como ponto de vista. Se no trecho de apresentação de Gerty citado no início deste texto o estilo era dominado por uma elegância inócua com apenas alguns breves interlúdios de caos verbal, aqui, a poucas páginas do clímax do episódio (e do clímax sexual de Bloom, proporcionado pela visão de Gerty à distância), o narrador parece ter dificuldades até mesmo em manter seu tom refinado na frase de abertura do parágrafo, que é tomada de assalto pela conjunção "e" / "and" a anunciar o surgimento de um morcego. É difícil determinar nesse ponto se o jogo narrativo do episódio consiste em uma espécie de cabo de guerra entre a suavidade lânguida do narrador à Cummins e a desordem verbal de Gerty, ou em um processo de imiscuição gradual entre ambos. ${ }^{6}$ Outra hipótese ainda seria a de considerar a "técnica" do episódio

6 Devlin (1985, p. 385) demonstra essa transformação gradual do narrador de "Nausicaa" ao elencar três referências aos gêmeos Tommy e Jacky Caffrey ao longo do episódio: "O primeiro trecho é matizado pela hostilidade das versões posteriores ('e eram gêmeos muito barulhentos e mimados' / 'very noisy and spoiled twins'), mas o ponto de vista externo da narrativa deixa incerta a origem de tal crítica velada. O segundo trecho é um discurso indireto livre, classificado como tal por 'Gerty pedia aos céus' / 'Gerty wished to goodness'. No exemplo final, a hostilidade alcançou seu ápice. Contendo um pedaço de pensamento 
de acordo com o esquema contido no James Joyce's Ulysses de Stuart Gilbert (1968): a tumescência - aqui com conotação obviamente sexual - do estilo, que vai se tornando mais caótico e indiferenciado até o seu ápice com os fogos de artifício, que se sobrepõem ao gozo masturbatório de Bloom, e a detumescência decorrente, quando o narrador parece sair de cena e ficamos a sós com os pensamentos do protagonista por várias páginas.

E a confusão não se manifesta apenas nas dificuldades de delimitação do estilo. Também os tipos de objetos enumerados quase parataticamente pertencem ao que inicialmente eram as diferentes esferas da personalidade de Gerty: de um lado, as aspirações às coisas do espírito, ao seu ideal de heroína de romance água-com-açúcar, e de outro, seus objetos mundanos e produzidos em série. Aqui, ainda mais do que em seu parágrafo de apresentação, somos surpreendidos pela abundância de coisas que vem à tona sempre que o texto cede espaço à voz do que cremos ser uma pessoa. Esse caráter reificador da subjetividade de Gerty pode ser notado em miniatura através do reaparecimento do termo "alabastro" / "alabaster", que fora utilizado anteriormente para descrever suas mãos e agora ressurge para adjetivar seu "bauzinho" / "pouncetbox"'. Dentro desse bauzinho, além das coisas por ela guardadas, encontram-se também "lindos pensamentos" / "beautiful thoughts" escritos em tinta violeta comprada na papelaria Hely's (a mesma dos homens-sanduíche de "Rochedos errantes", e onde Bloom costumava trabalhar); e tais pensamentos, a se julgar pelo título do poema citado por Gerty, dificilmente se distanciariam muito da elegância insípida que tenta se sobressair na descrição dos eventos da primeira parte do episódio.

Contudo, estivemos até agora tratando os dois trechos de "Nausicaa" citados como se fosse possível traçar uma linha divisória entre o narrador à Cummins e o discurso indireto livre de Gerty. Isto é, estivemos seguindo

fragmentado ('Macaquinhos mais vulgares que carne de vaca' / Little monkeys common as ditchwater') e sem uma etiqueta expositória, a segunda metade do trecho soa como o monólogo interior direto de Gerty MacDowell".

7 Karr Richards (1985, p. 760 e segs.) apresenta uma série de casos em que Gerty faz uso de termos pertencentes ao universo das mercadorias e de seus anúncios para descrever a si própria e as pessoas que a circundam. $\mathrm{O}$ "alabastro" acima mencionado, ainda que não se refira a este mesmo universo, é provavelmente devedor das leituras folhetinescas de Gerty, e sua lógica de funcionamento não se encontra tão distante daquela. 
de forma bastante direta a leitura de Hugh Kenner em "The Uncle Charles Principle”: um narrador que se deixa impregnar pelo vocabulário e pela sintaxe do personagem de quem está mais próximo, e que entrelaça descrições do ambiente com considerações subjetivas por meio de transições sutis que demandam um esforço de atenção do leitor para saber quem exatamente está falando. Passando para a distinção entre as duas instâncias narrativas, e ainda seguindo o modelo interpretativo de Kenner, teríamos, acima dessa dinâmica referente ao primeiro narrador, a arquipresença do arranjador, que se depara com as três garotas na praia e opta por um estilo elevado que tanto soa adequado quanto estabelece um contraponto irônico à carnalidade do encontro "amoroso" à distância entre a heroína Gerty MacDowell e o misterioso homem solitário, Leopold Bloom. Se a segunda parte do episódio, posterior ao clímax e ao momento em que Bloom se dá conta de que Gerty era coxa, consistiria em um longo monólogo interior praticamente ininterrupto, ou seja, a um momento do romance em que a figura do arranjador estaria fora de cena, sua primeira parte teria o arranjador como moldura paródica dentro da qual o Princípio do Tio Charles funcionaria normalmente.

Mas gostaríamos de sugerir que esse modelo de Kenner, ainda que precioso, poderia nesse ponto ser levado um pequeno passo adiante, em uma decorrência lógica de seus próprios pressupostos. Desse modo, não se trataria simplesmente, nessa primeira parte de "Nausicaa", de uma moldura proporcionada pela figura do arranjador, mas sim de um prisma paródico através do qual não apenas a figura de Gerty, com todo o seu repertório de mercadorias e leituras folhetinescas, mas a própria dinâmica de funcionamento dos episódios iniciais de Ulysses estaria sendo vista e violentamente atacada. Para dizer de outra maneira, não haveria na parte de "Nausicaa" dedicada a Gerty um entrelaçamento das “duas vozes” de Joyce, mas apenas a segunda voz - isto é, a do arranjador -, que estaria fazendo uma imitação particularmente grosseira do primeiro narrador, aquela "voz talvez mais hábil com arranjos de cena”, por baixo (ou por cima) de sua paródia de The Lamplighter, e com isso ameaçando sutilmente não apenas a possibilidade de descartá-lo, mas que talvez ele pudesse, retroativamente, passar a nunca ter existido em Ulysses. Passemos, então, a explorar os desdobramentos interpretativos de algumas das características do episódio que dão margem a 
esse tipo de afirmação: o modo como são feitas as transições entre exterior e interior de Gerty e a construção dessa interioridade.

\section{A REPRESENTAÇÃO ANTROPOMÓRFICA EM “NAUSICAA" E EM ULYSSES}

Foi ressaltado diversas vezes ao longo deste texto que as transições entre o exterior e o interior dos personagens de Ulysses, ou entre narração "neutra", discurso indireto livre e monólogo interior, são marcadas por uma sutileza que exige um esforço de atenção do leitor para diferenciar essas camadas narrativas. O trecho de "Calipso" brevemente citado algumas páginas atrás é sem dúvida representativo do estilo mais constante do romance, e que se encontra presente - ainda que com outras nuanças - já desde os seus primeiros parágrafos. Um leitor de primeira viagem, por exemplo, terá notável dificuldade logo nas primeiras páginas de "Telêmaco" em reconhecer que é Stephen Dedalus quem pensa "Chrysostomos", em um movimento narrativo ágil que focaliza os dentes de Buck Mulligan, garante um breve acesso aos pensamentos de Stephen, geralmente marcado por referências eruditas e religiosas, e deles sai rapidamente:

Ele olhou de canto ao alto e soltou um longo assovio baixo, um chamado, então suspendeu-se um instante em elevada atenção, regulares dentes brancos brilhando cá e lá em pontos dourados. Chrysostomos. Dois longos assovios fortes e estridentes cruzaram a calmaria. (JOYCE, 2012, p. 98)

He peered sideways up and gave a long low whistle of call, then paused awhile in rapt attention, his even white teeth glistening here and there with gold points. Chrysostomos. Two strong shrill whistles answered through the calm.

(JOYCE, 1961, p. 3) 
E essa mesma destreza narrativa se mantém durante a série de vinhetas que compõem "Rochedos errantes", ainda que servindo a propósitos diversos. Escolhendo quase ao acaso um trecho das andanças do padre Conmee, podemos notar procedimentos semelhantes, com um narrador que se deixa contaminar por sua linguagem, mas cujo trabalho quase maldoso de edição e paráfrase dos pensamentos torna difícil não ver o personagem sob uma luz desfavorável: "O padre Conmee abençoou-o [o marujo perneta] sob o sol pois sua bolsa continha, ele sabia, uma coroa de prata." (JOYCE, 2012, p. 381) / "Father Conmee blessed him in the sun for his purse held, he knew, one silver crown" (JOYCE, 1961, p. 219).

Porém, em nenhum dos dois trechos de "Nausicaa" aqui citados os deslocamentos na posição do narrador podem ser definidos como sutis. Especialmente no parágrafo de apresentação de Gerty, há uma quebra abrupta tanto na sintaxe quanto no universo de referências que assinala a presença de uma voz dissonante, e que começa a criar entraves cada vez maiores à dicção elevada que vinha tentando se firmar como voz narrativa, chegando a pontos como o do segundo trecho citado, em que dificilmente podemos encontrar uma frase inteira que não seja interrompida por seu fluxo desorganizado de palavras e coisas. Porém, isso não quer dizer que não haja espaço para sutilezas no episódio, pois o arranjador não se satisfaz em simplesmente emular um estilo elevado e anódino; mais do que isso, o que temos em "Nausicaa" é uma versão particularmente ruim desse estilo, meticulosamente trabalhada por meio de uma mistura de registros vocabulares díspares, uma sucessão de clichês dificilmente encontrável em um romance factível, indo desde a repetição de palavras "difíceis" como os "alabastro" de Gerty até um uso equivocado de conjunções, já mencionado acima, e mesmo de expressões fossilizadas da língua inglesa. É esse o caso, por exemplo, da "elevada atenção" / "rapt attention" de Buck Mulligan no trecho de "Telêmaco" citado logo acima, que se deteriora na Gerty "perdida em pensamentos" (JOYCE, 2012, p. 562) / "wrapt in thought" (JOYCE, 1961, p. 354), com o uso da forma arcaica do particípio passado de "wrap" (i.e. embrulhar) a reforçar seu uso cuidadosamente equivocado da expressão "rapt in thought" (e nesse caso a tradução de Galindo parece ter perdido a piada, que também foi perdida na edição online Concordance de Ulysses, que registra "rapt in thought"). 
Ora, se o nível de atenção ao detalhe no episódio se mantém elevado como de costume em detrimento dos deslocamentos entre interior e exterior de Gerty, talvez não seja forçado dizer, então, que tal distinção não seja muito significativa para o arranjador, que parece mais interessado nas sutilezas de seu próprio exercício de estilo do que na responsabilidade de garantir fluidez aos deslocamentos de posição narrativa, algo que normalmente ficaria a cargo de sua contraparte "convencional". Ou melhor, de um suposto ponto de vista do arranjador, a distinção entre exterior e interior não existe, pois não existe interioridade, já que, retomando novamente o argumento de Kenner, para essa figura tudo é estilo, e a única materialidade seria a de sua própria linguagem. Porém, se em última instância essa perspectiva é inegavelmente verdadeira, não só com respeito a Ulysses como a qualquer outra obra de ficção, isso não quer dizer que elas não possam - ou ao menos tenham podido até então - se comportar como se seus personagens realmente existissem; a diferença é que, no romance de Joyce, tal perspectiva é trazida para dentro da maquinaria narrativa, e cria algo como uma vontade própria.

A hipótese da abolição da distinção entre exterior e interior na parte inicial de "Nausicaa" não deixa de funcionar também como solução indireta para um problema interpretativo recorrente nas leituras do episódio, isto é, o de saber onde termina a voz do narrador e onde começa a voz de Gerty. Mesmo Kenner apresenta sua própria versão da questão, ao fazer um uso relativamente contraditório dos mesmos aspectos do episódio, em momentos diferentes de Joyce's Voices, tanto como forma de apresentar seu Princípio do Tio Charles quanto para expor sua primeira versão da figura do arranjador. Ou ainda, de acordo com Müller (2009, p. 389), haveria dois pressupostos implícitos na maioria dos textos críticos sobre Gerty: que sua parte em "Nausicaa" seria composta por um discurso indireto livre, e que, uma vez desfeito esse primeiro engano, o narrador seria determinado por ela, algo como sua própria fantasia de estilo elegante e açucarado.

Ainda que sua resposta a esse segundo pressuposto não seja das mais produtivas aqui, uma simples inversão dos termos de seus pressupostos a torna muito mais interessante para nossos propósitos: não seria o caso de a voz narrativa ser determinada por Gerty, mas, ao contrário, de o estilo determiná-la. Dito de outra forma, a voz narrativa não seria uma fantasia 
de Gerty, mas Gerty seria uma fantasia do estilo, ou do arranjador. Dessa perspectiva, a dificuldade em saber onde termina a voz do narrador e onde começa a voz de Gerty seria desfeita, já que não haveria uma "voz de Gerty". E isso por sua vez jogaria uma nova luz sobre o pressuposto inicial de "Nausicaa" como discurso indireto livre, com a diferença de que agora ele estranhamente passaria a pertencer ao arranjador, em algo como um eco retroativo do Malone beckettiano, que inventa Sapo-Macmann enquanto convalesce em sua cama.

Desfeitas - ou ao menos transfiguradas - as preocupações com uma divisão cristalina entre Gerty e narrador, a forma da primeira parte de "Nausicaa" pode finalmente ser reorganizada como um emaranhado de estilos discordantes. Em um sugestivo ensaio sobre o episódio em questão, Fritz Senn (1974, p. 305-306) apresenta uma tipologia desses diferentes estilos que a princípio desfaz sua pretensa uniformidade na desorganização de pelo menos sete vozes narrativas diferentes. As seis primeiras seriam: de um lado, além do narrador açucarado elevado, também sua versão mais singela, de vocabulário e estruturas sintáticas mais limitadas, com direito a uma inflexão específica dedicada à supressão de temas "impróprios"; de outro, a emulação ou referência à voz distinta empregada em slogans de propagandas, ou a colunas de conselhos práticos extraídos de revistas para mulheres, e mesmo às páginas sobre moda, de linguagem mais ornamentada, contidas nessas mesmas revistas. Os trechos do episódio citados até aqui poderiam ser decodificados de acordo com essas diferentes vozes sem grandes dificuldades, e o resultado seria a organização desse aparente caos verbal nos mesmos dois feixes distintos da literatura para mulheres da época já mencionados neste trabalho, um mais mundano e o outro mais sentimental, cujo horizonte comum é o da produção em série. Ou seja, também por este prisma a instância do arranjador acaba por se mostrar atenta apenas às suas próprias preocupações de estilo, reorganizando materiais muito próximos entre si em formatos diversos, ou dando uma aparência de diversidade a conteúdos praticamente inalterados. Por fim, vale notar que a sétima voz narrativa seria constituída por suas marcas mais radicalmente pessoais, caracterizadas por rompantes quase involuntários de agressividade e mesquinhez direcionados tanto às companheiras quanto às crianças de quem toma conta. Esse aspec- 
to negativo como traço último de subjetividade possível não deixa de ser significativo, e tem como corolário o fato de que sua potência é geralmente desagregadora, sempre minando a já frágil sintaxe das frases.

Nesse ponto, seria possível levantar a objeção de que nossa hipótese se constrói em torno de um movimento de desintegração da subjetividade ainda incipiente na época da publicação de Ulysses, o que tornaria sua representação no romance algo excessivamente visionário, para não dizer um pouco forçado. Mas essa ressalva emudece na medida em que a leitura aqui produzida busca funcionar também como uma resposta diante do processo de envelhecimento do romance. Afinal, os dois feixes em torno dos quais se organizam os malabarismos estilísticos do narrador de "Nausicaa" dificilmente eram tão visíveis quanto o são agora, quando estamos munidos de um guia do porte do Ulysses Annotated de Don Gifford, que, ao catalogar cada um dos slogans citados por Gerty, ou atestar a veracidade das dicas pseudocientíficas (e, por que não, pseudomísticas) que regem sua vida, não deixa de contribuir de forma indireta, justamente por sua promessa de clareza total, para que muitos de seus conteúdos se tornem irremediavelmente opacos. Isto é, o próprio processo de absorção de Ulysses pela cultura contribui para que parte de seus conteúdos fiquem neutralizados para os leitores contemporâneos - no caso em questão, fazendo com que qualquer germe de subjetividade contido nos significantes "Gerty MacDowell” não consiga ganhar vida.

Todavia, conceber dessa forma o episódio - bem como suas implicações para o romance como um todo - acaba por torná-lo especialmente estéril, avançando a ideia mais usual de Ulysses como um livro que interpõe entre leitor e acontecimentos/personagens uma mata densa de estilo até o limite. Na perspectiva aqui delineada, a possibilidade de se representar formas de subjetividade no romance, e em última instância a própria categoria dos personagens, são postas em xeque. Por outro lado, não parece ser isso o que ocorre em Ulysses. Conforme já defendido no decorrer desse texto, o peso variável dedicado às diferentes vozes narrativas ao longo do livro faz com que, mesmo quando quase totalmente suprimidas, sejam capazes de causar fortes efeitos por meio de breves vislumbres que delas temos por conta da força da caracterização de suas interioridades nos episódios iniciais. Mesmo não existindo efetivamente, a mestria de Joyce sobre os procedimentos for- 
mais cria efeitos de interioridade dos personagens que, por sua vez, produzem efeitos nos leitores. $\mathrm{O}$ acúmulo de detalhes na caracterização de Bloom, a forma como seu sofrimento é geralmente apenas sugerido e contornado, sua porosidade e abertura para os estímulos sensoriais, a velocidade de suas associações, aliada a uma ingenuidade - ou até ignorância - por vezes tocante, e mesmo a sensação causada pelo arranjador de que o universo conspira contra Bloom, tornam difícil admitir que se trata apenas de um jogo gratuito e inorgânico dos significantes que compõem o romance, por mais que em outra de suas instâncias possa ser precisamente isso que se afirme.

Com efeito, mesmo que Ulysses efetivamente consistisse apenas em tal jogo de significantes - isto é, que a leitura aqui construída referendasse integralmente a ideia de Kenner, certamente devedora do pós-estruturalismo em voga na época de publicação de seu livro de crítica sobre Joyce, de que no romance "tudo é linguagem" e nada além disso -, restaria mesmo assim um último reduto para uma manifestação, ainda que mais rarefeita, de uma representação antropomórfica capaz de garantir alguma projeção, talvez essencial, de subjetividade. Pois, ao mesmo tempo em que Gerty é dessubjetivada e tornada inorgânica, em um processo que aponta metonimicamente para toda a categoria dos personagens, o estilo do arranjador, de certa forma dela se alimentando, torna-se desse modo mais vívido, transformando-se em uma categoria que ultrapassa a do narrador. Afinal, muito do que foi dito até aqui sobre a figura do arranjador poderia ser transposto, com alguma imaginação interpretativa, para uma espécie muito particular de Bildungsroman do estilo em Ulysses, com direito a uma trama própria repleta de desenvolvimentos, tendo como clímax possível um gesto característico de tomada de consciência que garantiria assim à forma da segunda parte do romance muitas de suas peculiaridades. Nessa perspectiva curiosa, todas as relações de identificação e projeção essenciais à organização de um enredo se encontrariam em alguma medida salvaguardadas, mesmo que em segundo grau ou de forma reduzida.

Para que uma estratégia interpretativa como essa se faça necessária, contudo, é preciso que ao menos parte do processo de neutralização da subjetividade de Gerty seja capaz de contaminar os demais personagens de Ulysses, e em especial seu protagonista, Leopold Bloom. Mas, se um ataque frontal à figura antropomórfica de Bloom dificilmente surtiria tal efeito desagrega- 
dor - e, na verdade, esse tipo de ataque é constante em Ulysses -, uma crítica velada por meio da paródia indireta aos procedimentos que constituem seu efeito de interioridade pode ter mais sucesso. E não seria esse o caso de Gerty, com suas aspirações artísticas lowbrow (ou seria lower-middlebrow?), seu gosto pelo sentimentalismo barato, o que há nela de mais subjetivo sendo representado pelas coisas que possui e pelas revistas de que gosta? Mesmo o acesso que temos às suas dores mais profundas é caracterizado pela banalidade do clichê e pela onipresença das mercadorias, o que dificulta o estabelecimento de uma relação imediata, e faz ressoar no sofrimento de Bloom pelo adultério de Molly uma nota indireta e irônica de lugar comum, a primeira exclamação quase ecoando o "For Raoul!" lido por Bloom no romance pornográfico que adquirira para Molly, e que inevitavelmente compara com sua relação com Blazes Boylan: "Como era triste aos ouvidos da pobre Gerty! Tivesse seu pai conseguido evitar as garras do demônio da bebida, fazendo um voto ou tomando aqueles pós para a cura do vício da bebida no hebdomadário Pearson's, ela poderia agora estar rodando em sua carruagem, acima de todas." (JOYCE, 2012, p. 561-562) / "How sad to poor Gerty's ears! Had her father only avoided the clutches of the demon drink habit cured in Pearson's Weekly, she might now be rolling in her carriage, second to none." (JOYCE, 1961, p. 354)

Recuando um pouco, mas ainda tratando da constituição da subjetividade de Gerty, a hipótese interpretativa aqui desenvolvida apresenta a vantagem inesperada de considerar seu apreço pelas aparências de um ângulo que não é reduzido ao simples moralismo, com uma condenação da futilidade de Gerty, ou mesmo, em certos momentos do texto, de sua mesquinhez rancorosa. Ao contrário, sua preocupação com as aparências - seja com relação a seus traços físicos ou com sua obsessão em manter uma espécie de verniz de decoro vitoriano -, de nossa perspectiva, se revela como uma característica de conteúdo que é determinada por um princípio formal: a heroína de "Nausicaa" se preocupa com a forma como é vista por não ter outra escolha, porque ela apenas parece $e$ não é, em sentido enfático, alguém, sendo desprovida de uma interioridade que ultrapasse os moldes da paródia que habita. Nesse sentido, o acúmulo caótico de coisas pertencentes ao mundo das mercadorias sempre que sua subjetividade parece surgir, nos interstícios da 
elegância açucarada à Cummins, também se mostra sob uma nova luz: seus objetos não servem como cifras da interioridade de Gerty, mas aparecem em seu lugar, pois não há nada por baixo deles, e ela é reduzida ao conjunto de coisas que possui ou quer possuir, ou a um conjunto vago de idiossincrasias - o que não deixa de ressoar indiretamente na caracterização de Bloom. Com efeito, Gerty MacDowell parece se constituir como uma espécie de síntese involuntária entre o fetichismo da mercadoria e o fetichismo freudiano (FREUD, 1992 [1927]): isto é, uma relação entre seus objetos (possuídos ou imaginados) que é percebida erroneamente como uma relação entre pessoas - ou a constituição de sua subjetividade - que, por sua vez, não existe. $\mathrm{Ou}$, dito de outro modo, a própria Gerty consiste no acúmulo de objetos que servem para recobrir sua falta de interioridade, tentando fazer com que deles emane uma característica (social) que é alheia a eles.

Após a passagem pela cena com Gerty, o monólogo interior de Bloom ocupa ininterruptamente a narrativa por diversas páginas, iluminando por contraste a ausência desse mecanismo estilístico das páginas anteriores. Contudo, sua proximidade com a imensa carga de clichês contida na primeira parte de "Nausicaa" sublinha não só o que dela se diferencia - como a agilidade das associações e o acúmulo de referências que se espalha por todo o romance, garantindo uma espécie de terra firme para a interioridade de Bloom se fincar -, mas também o que dela se aproxima. Pois Bloom também tem suas aspirações artísticas suscitadas por algo que lê no jornal, na brilhante cena em que alivia os intestinos em "Calipso", mas nada nos leva a crer que sua produção narrativa seria muito superior à de Gerty. No mínimo, parte de sua projeção utópica, frequentemente relembrada e longamente descrita em "Ítaca", é fruto de um outro anúncio de jornal lido em "Calipso", sobre a cooperativa Agendath Netaim, e muito de seu "temperamento científico" é certamente restrito às revistas das quais era ávido leitor. E ainda um outro contraponto significativo entre Bloom e Gerty diz respeito à onipresença das mercadorias e slogans propagandísticos permeando o pensamento desta: a propaganda consiste no métier de Bloom, e ele volta e meia se encontra pensando em como fazer anúncios mais eficientes - mais uma vez, o inventário de "Ítaca" menciona longamente essa propensão -, que talvez fossem registrados por Gerty e passassem a compor mais um pedaço de sua subjetivida- 
de. Por mais que haja uma diferença entre ambos - Bloom como produtor, Gerty como consumidora de anúncios -, ela não parece resultar apenas em uma afirmação da superioridade de Bloom, como quer Karr Richards (1985, p. 773), ao dizer que ele mantém uma capacidade "de aceitação e criação consciente e celebratória dessa cultura [material]"; ao contrário, talvez se trate da aceitação de uma presença que começa a se anunciar como incontornável, e que demanda no mínimo algum tipo de resignação.

Por fim, Bloom e Gerty não são os únicos a serem atravessados por uma lógica (ainda incipiente) da propaganda no contexto de Ulysses. Stephen Dedalus, dominado por elucubrações de outra ordem, certamente poderia ser contraposto a Gerty como forma de estabelecer ao menos dois tipos divergentes de relação com os objetos materiais - uma pela via do símbolo, outra pela via de uma materialidade fetichizada. Porém temos em mente nesse ponto a figura de James Joyce, cujas estratégias para convencer uma comunidade de leitores de que o romance que escrevera não era um simples amontoado caótico de palavras, algo desprovido de qualquer coerência, não deixam de lembrar um pouco uma proto-campanha de marketing, com direito à polêmica decorrente de esquemas interpretativos divergentes fornecidos a pessoas diferentes (Carlo Linati e Stuart Gilbert) também como forma de fomentar a discussão em torno de si, passando pela discordância - que poderia ter sido recebida em espírito de "não existe propaganda negativa” - entre Richard Aldington e T.S. Eliot sobre se Ulysses faria afinal algum sentido. E não nos esqueçamos de que tais tentativas de divulgação se deram em circunstâncias curiosas, tais como definidas por Hugh Kenner logo no início de Joyce's Voices (1978, p. 1): as de que "se pedia a leitores que nunca tinham visto uma cópia [de Ulysses] que assumissem que o livro de Joyce era aquilo que o protagonista do momento dissesse que era."

Quase 80 anos após sua publicação, o livro de Joyce se encontraria novamente em uma situação curiosa, que provavelmente perdura até os nossos dias e não será mudada tão cedo. Sentada em frente à sua escola, uma das protagonistas do seriado Gilmore Girls parece ler o James Joyce's Ulysses de Stuart Gilbert por exatos dois segundos - infelizmente, é impossível saber se o livro está aberto no capítulo sobre "Nausicaa". O volume quase imperceptível aponta no máximo para duas coisas: primeiro, é claro, para o romance de Joyce, que 
por sua vez serve como cifra de que a heroína é intelectualizada; e segundo, de forma mais sutil - como se esse tipo de atenção ao detalhe emanasse inevitavelmente do livro -, que leva seus estudos realmente a sério, chegando a consultar uma bibliografia secundária confiável ainda na escola. Ela é então interrompida por sua amiga, as duas conversam sobre algo relacionado ao enredo da série, e o livro ainda aberto em suas mãos é então guardado em uma sacola, algum princípio de verossimilhança nos levando a pensar que o Ulysses ali estaria. Caso esteja - e também é algo que nunca saberemos -, a sacola poderia ser o bauzinho de Gerty, os lindos pensamentos de Joyce agora substituindo os de Cummins para o que poderia ser uma nova iteração da princesa Nausicaa. O livro invisível dentro da sacola inverte a situação descrita por Kenner, mas não consegue alterá-la: mesmo onipresente e acessível em sua materialidade, fora do círculo de iniciados e da "Joyce industry", ele parece permanecer inerte, uma cifra que signica simplesmente cultura, talvez Cultura. Se fosse lido pela heroína de Gilmore Girls, revelaria a série como a paródia não-intencional que ela não sabe que habita. Ataques como o de um Paulo Coelho estão fadados a acontecer de tempos em tempos, e se ele inesperadamente acerta em parte ao dizer que Ulysses "é só estilo. Não tem nada ali." não sabe que Joyce já sabia disso. Se seu romance estiver condenado a perecer, ele merece ao menos o privilégio de ter sido o primeiro a declarar a sentença.

\section{REFERÊNCIAS}

DEVLIN, Kimberly. The Romance Heroine Exposed: 'Nausicaa' and The Lamplighter. James Joyce Quarterly, vol. 22, n.4, p. 383-396, 1985.

FREUD, Sigmund. Fetichismo [1927]. In: Obras Completas, vol. XXI. Buenos Aires: Amorrortu Editores, 1992.

GIFFORD, Don. Ulysses Annotated - Notes for James Joyce’s Ulysses. Berkeley: Los Angeles: London: University of California Press, 2008.

8 Fonte: http://ultimosegundo.ig.com.br/cultura/livros/2012-08-09/nao-tem-nada-ali-diz-paulo-coelho-sobre-ulysses-de-james-joyce.html . 
GILBERT, Stuart. James Joyce’s Ulysses. New York: Random House, 1968.

HAYMAN, David [1970]. Ulysses: The Mechanics of Meaning. Madison: The University of Wisconsin Press, 1982

JOYCE, James. Ulysses. New York: Random House, 1961.

. Ulysses. Trad. de Caetano W. Galindo. São Paulo: Penguin/Companhia das Letras, 2012.

. Ulysses. Disponível em: http://www.doc.ic.ac.uk/ rac101/concord/ texts/ulysses/ulysses.cgi?word=Ulysses. Acesso em: 05 fev. 2014.

KARR RICHARDS, Thomas. Gerty MacDowell and the Irish Common Reader. $E L H$, vol. 52, n.3, p. 755-776, 1985.

KENNER, Hugh. Joyce's Voices. Berkeley: Los Angeles: Londres: University of California Press, 1978.

. Ulysses. Baltimore e Londres: The Johns Hopkins University Press, 1980.

MÜLLER, Timo. Gerty MacDowell, Poetess: Butler's 'The Authoress of the Odyssey' and the Nausicaa Episode of 'Ulysses". Twentieth Century Literature, vol. 55, n.3, p. 378-392, 2009.

SENN, Fritz. Nausicaa. In: HART, Clive; HAYMAN, David (Org.). James Joyce's Ulysses - Critical Essays. Berkeley: University of California Press, 1974. p. 277-311. 